\title{
О ПОВЕДЕНЧЕСКОЙ МОДЕЛИ ЛИН-УПРАВЛЕНИЯ ПРЕДПРИЯТИЕМ, ОСНОВАННОЙ НА ПРИНЦИПАХ ДЕМИНГА
}

\author{
(c) 2019 Морунов Виталий Викторович \\ кандидат экономических наук, доцент кафедры менеджмента и гуманитарных дисциплин \\ Бугульминский филиал \\ Казанский национальный исследовательский технологический университет \\ 423243, г. Бугульма, ул. Красноармейская, д. 9 \\ E-mail:v_morunov@mail.ru \\ (c) 2019 Ахмедзянова Файруза Камиловна \\ кандидат педагогических наук, доцент кафедры технологических машин и оборудования \\ Бугульминский филиал \\ Казанский национальный исследовательский технологический университет \\ 423243, г. Бугульма, ул. Красноармейская, д. 9 \\ E-mail:kamilovna@yandex.ru
}

В статье предложена модель управления организацией, функционирующей по правилам бережливого производства, основанная на принципах Деминга, а также описано сравнение её с традиционной моделью управления. Также приведены 14 принципов Деминга и обоснована эффективность применения данных принципов в рамках предлагаемой модели.

Ключевые слова: модель управления предприятием, бережливое производство, принципы Деминга, персонал.

Система бережливого производства (англ. lean production / lean manufacturing) или система лин-менеджмента - система управления организацией, основанная на формировании абсолютно другого сознания персонала, направленного на снижение производственных и прочих потерь на всех уровнях ее функционирования.

В основе философии управления Эдварда Деминга - соавтора цикла Шухарта-Деминга (PDSA или PDCA) - лежат 14 принципов управления предприятием, соблюдение которых, по мнению Деминга, способно привести менеджмент любой компанией к максимальной эффективности:

1) постановка цели постоянного развития и совершенствования компании;

2) принятие новой философии бизнеса;

3) устранение зависимости от массового контроля при достижении качества;

4) отмена практики выбора поставщиков только на основе цены на их продукцию;

5) постоянное совершенствование всех производственных процессов;

6) введение в практику современных подходов к подготовке и переподготовке всех работников;
7) усвоение и учреждение лидерства как метода работы менеджеров;

8) поощрение эффективных двусторонних связей и использование других средств для искоренения страхов, опасений и враждебности внутри компании;

9) отмена барьеров между подразделениями, службами, отделами;

10) отказ от лозунгов, проповедей и призывов к работникам лучше работать;

11) исключение произвольных нормативов и количественных заданий;

12) устранение препятствий, лишающих людей профессиональной гордости и возможности гордиться результатами своего труда;

13) поощрение стремлению к образованию;

14) формулирование позиций, чтобы каждый в компании участвовал в программе преобразований (и, прежде всего, высшее руководство).

Как результат, модель управления предприятия, построенной на лин-технологиях, основанная на принципах Деминга (для целей настоящей статьи назовем такую модель «развивающий менеджмент»), в альтернативу устоявшейся модели управления (назовем её «традиционный менеджмент») приводит к сле- 
дующим результатам:

- минимизация стрессовых ситуаций в коллективе компании;

- саморазвитие всех сотрудников без исключения;

- повышение значимости деятельности работников и возможностей реализации данных идей;

- искоренение страхов и повышение командного подхода к решению задач;

- прозрачность предлагаемых и внедряемых моделей и решений;

- готовность к развитию всего персонала, включая руководящий;

- другие результаты.

Основной метод традиционного менеджмента - метод «кнута и пряника», т.е. в случае наступления неоднозначной ситуации (например, появления проблемы), обычно происходит выявление виновного и его наказание. При этом, в случае проявления новых идей происходит либо занижение (или не проявление) значимости их автора, либо несущественная «одноразовая» мотивация (например, премия без дальнейшего внедрения идеи). Модель развивающего менеджмента, принцип которого заключается в отсутствии смысла поиска виновного, основывается всегда в поиске решения возникшей проблемы, т.е. вместо вопроса «кто виноват?» (как в традиционном менеджменте) в развивающем задается вопрос «что виновато?». В этом, считаем, основная разница между двумя моделями управления: развивающий менеджмент предлагает отказаться от самой идеи наказания: наказание сотрудника по модели 98/2 (98\% ошибок происходит не из-за людей, а по причине сбоев в работе системы управления [1, с.16]) исправит в лучшем случае $2 \%$ ошибок и не улучшит сам бизнес. Неисполнение задачи сотрудниками может быть связано и с их высокой загрузкой, что также может являться системной проблемой.

В дополнение к сказанному выше, добавим, что развивающий менеджмент также руководствуется фразой Деминга: «где бы не появлялся страх - там появляются ложные числа» [1]. Речь здесь идет, прежде всего, о предоставлении руководству более «выгодной» (для подчиненных) информации: «выгода» с точки зрения починенных заключается в минимизации применения к ним мер ответственности за случившееся, пусть и не по их вине, осложнение. Ложная информация сильно мешает руководителю для принятия оперативных и, самое главное, правильных решений.

В развивающем менеджменте социальная атмосфера в коллективе строится на совершенно другом - эффективном уровне: сотрудники доброжелательны, открыты для общения, им интересна их работа, нравится коллектив. Руководство здесь из начальников, надзирателей, менторов превращается в настоящих лидеров (наставников, тренеров (метод коучинга)).

Развивающий менеджмент позитивно меняет содержание и характер работы и первого лица, которому нравится работать в такой системе, он сконцентрирован на вопросах стратегии, на методах дальнейшего развития новых отношений в коллективе.

Развивающий менеджмент клиенториентирован, он реагирует на запросы рынка, тем самым повышает качество своего продукта.

Развивающий менеджмент признает право сотрудников ошибаться, он рассматривает ошибки, как явление, из которого компания ещё не извлекла выгоду, каждая ошибка - «бриллиант», это носитель информации о сбоях и недостатках в процессах системы. Это путь к повышению качества продукции компании.

В развивающем менеджменте увольнение - это не решение, это бомба замедленного действия. Это негативный пример и для новых сотрудников, понимающих, что увольнение неотъемлемый элемент управления нового руководства. В развивающем менеджменте один из способов мотивации персонала - это пожизненный найм, т.е. компания стремится развивать своих сотрудников, но не препятствовать их увольнению в случае желания последних уйти на другую работу. Наоборот, изучаются вопросы - почему сотрудник выбирает другую компанию? При пожизненном найме у сотрудников компании появляется чувство причастности ко всем делам фирмы, ответственность за ее процветание, желание внести свой вклад. Уверенный в своем «завтра» человек способен работать по-настоящему творчески и с полной отдачей. Сотрудник, получающий от своей работы удовольствие, работает намного эффективнее и качественнее.

В традиционном менеджменте имеются иерархические уровни управления (система - «начальник - подчиненный»), которая тормозит совершенствование системы. Здесь самым «знающим» выступает начальник, а реальный специ- 
алист вынужден отодвинуться на второй план. Развиваются интриги, конкуренция, жалобы на сотрудников. В результате «клиент», «потребитель» отодвигаются на второй план. В развивающем менеджменте самое главное - это клиент и качество продукции.

В традиционном менеджменте - все новшества воспринимаются «в штыки», поскольку спускаются сверху. В результате - вся работа становится тяжелым бременем, все сотрудники работают в стрессе.

Развивающий менеджмент рассматривает иерархию как инструмент построения горизонтальной организации компании и механизм поддержания нормального функционирования нового организационного устройства. Миссия руководителя - помочь выстроить горизонтальные отношения в системе на основе действующих процессов, стереть барьеры между подразделениями.

В развивающем менеджменте в системе важно, чтобы сотрудники брали на себя ответственность за решение текущих вопросов, за совершенствование бизнес-процессов. На этом фоне традиционный менеджмент - бюрократическая неповоротливая тяжеловесная машина, гасящая инициативу творческий порыв своих сотрудников.

Таким образом, развивающий менеджмент строится на принципах производственной демократии, сотрудничества и контролируемой самоуправляемости организации.

В модели развивающего менеджмента смысл управления - это постоянное совершенствование, в традиционном - прибыль.

В развивающем менеджменте считают, что если меняется смысл деятельности организации - меняется смысл деятельности каждого сотрудника; при этом выделяют 3 направления для совершенствования:

1) снижение количества дефектов;

2) уменьшение вариабельности (т.е. максимальная стандартизация);

3) повышение эффективности.

В концепции развивающего менеджмента - другая материальная мотивация персонала: если в традиционном - «мне платит начальство», в развивающем - «я зарабатываю и помогаю заработать компании».

В развивающем менеджменте приветствуется добровольная ротация между отделами, что позволяет сломать стереотипы и наладить кон- такты между отделами. Т.е. сотрудник должен почувствовать как часть фирмы, чувствовал себя ответственным за все, что в ней происходит.

Деятельность сотрудника в развивающем менеджменте нацелена на реализацию миссии фирмы и осознанного представления о деятельности компании, а высокая цель труда сама по себе побуждает к более эффективной работе.

В модели развивающего менеджмента работа строится на командной основе на всех уровнях, что приводит к синергетическому эффекту, который многократно усиливает интеллектуальный потенциал сотрудников. В развивающий менеджмент - командный стиль работы, который пронизывает деятельность всей компании сверху донизу. В развивающем менеджменте именно команда вырабатывает новые идеи и осуществляет их реализацию. В каждом бизнес-процессе существует своя команда, которая отвечает за реализацию постоянного его совершенствования.

В работе с внедренной моделью развивающего менеджмента:

- фирма информационно открыта для сотрудников, это позволяет избежать слухов и сплетен (например, о зарплате руководителей). В закрытой информационной системе - закрытость начинает распространяться и на клиентов;

- от сотрудников ожидается инициативность, творчество, вместо простого выполнения функций, ожидается готовность работать на тех участках, которые наиболее важны для компании в данный момент времени, а также возложить на себя ответственность за новые направления работы;

- план-директива рассматривается как зло: правильно построенная система мотивации заменяет плановые директивы, которые могут спровоцировать снижение качество продукции, работ, услуг. При этом КПЭ (ключевые показатели эффективности) устанавливаются самостоятельно, это всё равно, что договоренность между компанией и работником о достижении показателя, за которую работник взял на себя ответственность. Такая система имеет свои плюсы;

- не надо подталкивать достижением плановых показателей;

- имеется согласование общего плана, основанного на КПЭ каждого сотрудника, а, значит, согласованного на всех уровнях;

- создается система сквозной мотивации всех сотрудников на повышение эффективности. 
В развивающем менеджменте в части отношения к поставщикам - развивается долгосрочное партнерство, поскольку такая политика развивает уверенность в поставщике и заставляет его повышать ответственность за качество и надежность для покупателя. От поставщика при этом требуется:

- соответствия определенному уровню качества;

- готовности преодолевать юридические преграды покупателя, т.е. должен нам помогать в вопросах качества, если вопросы касаются его товаров, работ и услуг;

- готовность к совершенствованию (он должен развиваться вместе с покупателем, одновременно - повышать и свое качество);

- открытость цены, чтобы клиент понимал его уровень соответствия рынку, уровень его рентабельности, уровень его «жертвенности» по отношению к покупателю.

В системе развивающего менеджмента считают, что в любой организационной структуре должна функционировать служба качества. При этом, система TQM (англ. total quality management - общеорганизационный метод непрерывного повышения качества всех организационных процессов) должна входить в новую структуру управления организацией, как обязательная функция управления. Здесь понимается, что чтобы компания стала конкурентоспособной - она должна быстрее расти, быть эффективнее, товары и услуги ее должны быть лучше (качественнее) и дешевле [3].

В развивающем менеджменте система принципов Деминга - основа для формирования внутрифирменных стандартов и концепций, подходов и методов действий.

О лидерстве в модели развивающего менеджмента.

Лидерство - ключевой метод менеджмента, это основное различие от модели с традиционным менеджментом. Главная цель лидерства - смотреть не на последствия, а анализировать причины. Лидерство - это принятие сотрудником ответственности за всю компанию, за всю команду, за достижение ею конкретных весомых результатов. При этом, иерархия задается системой ответственности: у одних она более широкая, у других - более узкая.

Здесь нельзя действовать через голову лидера: руководитель более высокого ранга не должен давать указания сотруднику, минуя его непосредственного начальника. Не все готовы взять на себя бремя лидерства, поскольку оно требует работы мысли, активности и инициативности.

\section{Библиографический спосок}

1. Фидельман Г.Н., Дедиков С.В., Адлер Ю.П. Альтернативный менеджмент: Путь к глобальной конкурентоспособности. Москва. 2005. 186 с.

2. Адизес И. К. Идеальный руководитель: почему им нельзя стать и что из этого следует. Москва. 2014. 169 с.

3. Фокс Д. Как стать сильным конкурентом: Тактики достижения рыночного преимущества. 2011. 88c.

4. Морунов В.В. Теоретико-методологическое обоснование проведения централизации управленческих функций сотрудников организации, имеющей в своей структуре обособленные структурные подразделения // Финансовая экономика. 2018. № 7 (ч. 1). С. 79-81. 